\title{
TEPA impregnation of electrospun carbon nanofibers for enhanced low-level $\mathrm{CO}_{2}$ adsorption
}

\author{
Jie Wang ${ }^{1}$, Adedeji Adebukola Adelodun ${ }^{2}$, Jong Min Oh ${ }^{1}$ and Young Min Jo ${ }^{1^{*}}$ (D)
}

\begin{abstract}
The $\mathrm{CO}_{2}$ adsorption selectivity of plain activated carbon nanofibers (ANF) is generally low. For enhancement, nitrogen functionalities favorable for $\mathrm{CO}_{2}$ adsorption are usually tethered to the ANF. In the current study, we adopted chemical impregnation using $0.5 \mathrm{wt} \%$ tetraethylenepentamine (TEPA) solution as an impregnant. To enhance the impregnation of TEPA further, preliminary oxidation of the nanofibers with $70 \% \mathrm{HNO}_{3}$ was conducted. The effects of $\mathrm{HNO}_{3}$ and TEPA treatments on the modified ANFs were investigated for physical (using $\mathrm{N}_{2}$ monosorb, thermogravimetric analyzer, scanning electron microscopy) and chemical (X-ray photoelectron spectrometer) changes. From the results, we found that although TEPA impregnation reduced the specific surface area and pore volume of the ANFs (from 673.7 and 15.61 to $278.8 \mathrm{~m}^{2} / \mathrm{g}$ and $0.284 \mathrm{~cm}^{3} / \mathrm{g}$, respectively), whereas the $\mathrm{HNO}_{3}$ pre-oxidation increased the number of carboxylic groups on the ANF. Upon TEPA loading, pyridinic nitrogen was tethered and further enhanced by pre-oxidation. The surface treatment cumulatively increased the amine content from $5.81 \%$ to $13.31 \%$. Consequently, the final adsorption capacity for low (0.3\%) and pure $\mathrm{CO}_{2}$ levels were enhanced from 0.20 and 1.89 to 0.33 and $2.96 \mathrm{mmol} / \mathrm{g}$, respectively. Hence, the two-step pre-oxidation and TEPA treatments were efficient for improved $\mathrm{CO}_{2}$ affinity.
\end{abstract}

Keywords: Low $\mathrm{CO}_{2}$ capture, Physical activation, Tetraethylenepentamine (TEPA), $\mathrm{HNO}_{3}$ oxidation, Surface chemistry

\section{Introduction}

Besides the highest contributor to anthropogenic global warming, $\mathrm{CO}_{2}$ could also be harmful at relatively low concentrations, especially in confined indoor spaces, depending on whether they are, stationary (such as offices, homes, and subway stations) or mobile environments (such as cars, airplane, and submarines) [1, 2]. Therefore, the control of indoor $\mathrm{CO}_{2}$ at $1,000 \mathrm{ppm}$ or higher concentrations [the limit set by the Environmental Protection Agency (EPA)] require efficient technologies for safe indoor activities with a long duration [3].

In the last two decades, indoor air quality (IAQ) researchers have intensified efforts to improve the

\footnotetext{
*Correspondence: ymjo@khu.ac.kr

1 Department of Applied Environmental Science, Kyung Hee University, 1732, Deogyeong-daero, Giheung-gu, Yogin-si, Gyeonggi-do 17103, Republic of Korea

Full list of author information is available at the end of the article
}

adsorption of elevated levels of indoor $\mathrm{CO}_{2}$. The use of amine-based or amine-functionalized adsorbents is popular among such research approaches [4]. Usually, these adsorbents are fabricated using grafting or the impregnation method [5]. Some researchers have confirmed that both impregnation and grafting are effective for increasing the $\mathrm{CO}_{2}$ adsorption capacity of carbonbased sorbents [6-8]. Furthermore, Na Rao et al. [9] compared the two methods and their results showed that impregnation is superior to grafting with respect to amine-loading efficiency and eventual $\mathrm{CO}_{2}$ adsorption capacity. Impregnation of amines is usually a wet process during which amines are physically adhered onto a support via non-covalent attachment to improve the affinity of the support for a target adsorptive [10]. For example, the effects of three types of organic amines (i.e., diethylenetriamine, triethylenetetramine, and tetraethylenepentamine (TEPA)) on $\mathrm{CO}_{2}$ adsorption capacity has been 
reported [11]. The results showed that if TEPA was used as a chemical impregnant for a solid support, it could improve $\mathrm{CO}_{2}$ adsorption of the support.

TEPA is a linear molecule bearing five amine groups per molecule: two primary amines $\left(\mathrm{RNH}_{2}\right)$ and three secondary amine $\left(\mathrm{R}_{2} \mathrm{NH}\right)$ groups. The mechanism by which primary amine and secondary amine react with $\mathrm{CO}_{2}$ are expressed in Eqs. (1) and (2), respectively [5]:

$$
\begin{aligned}
& \mathrm{CO}_{2}+2 \mathrm{RNH}_{2} \leftrightarrow \mathrm{RNH}_{3}{ }^{+}+\mathrm{RNHCOO}^{-} \\
& \mathrm{CO}_{2}+2 \mathrm{R}_{2} \mathrm{NH} \leftrightarrow \mathrm{R}_{2} \mathrm{NH}_{2}{ }^{+}+\mathrm{R}_{2} \mathrm{NCOO}^{-}
\end{aligned}
$$

However, to achieve optimum wet impregnation, adequate knowledge of certain properties of the support such as the specific surface area, pore size, pore structure, and surface $\mathrm{pH}$ is essential. In general, a porous support with a relatively high specific surface area and large pore volume has a good potential for organic amine immobilization [11].

In this study, various activated nanofibers (ANFs) were prepared by either physical or chemical activation. Further, all the ANFs were impregnated with TEPA solution. To improve the TEPA loading, some ANFs were pre-oxidized with nitric acid solution prior to impregnation.

\section{Experimentals}

\subsection{Consumable materials}

Polyacrylonitrile (PAN, M.W. $=150,000 \mathrm{~mol} / \mathrm{g}$ ), $70 \%$ nitric acid, and tetraethylene pentamine (TEPA, Reagent grade) were purchased from SIGMA-ALDRICH, Co. in Korea. $\mathrm{N}, \mathrm{N}$-dimethylformamide (DMF), potassium hydroxide, and ethanol solution were procured from DAEJUNG CHEMICALS \& METALS CO., Seoul, Korea. All of the reagents were used as-received.

\subsection{Preparation of PAN-based carbon nanofibers}

First, two types of PAN solutions were prepared in weight ratios: (i) PAN/DMF solution (PAN:DMF $=1: 9$ ) for physical activation and (ii) KOH/PAN/DMF solution (PAN:DMF:KOH = 1:9:0.01-0.05) for chemical activation. Each polymer solution was electrospun at an inject velocity of $1.5 \mathrm{~mL} / \mathrm{h}$ under $18 \mathrm{kV}$. The electrospun nanofiber was stabilized in an oven at $200{ }^{\circ} \mathrm{C}$ for $4 \mathrm{~h}$ before cooling to room temperature. Then, cooling it to room temperature, it was transferred into a tubular quartz reactor and heated at a ramping rate of $5{ }^{\circ} \mathrm{C} / \mathrm{min}$ to $800{ }^{\circ} \mathrm{C}$ under $\mathrm{N}_{2}$ flow that was fed at $200 \mathrm{~cm}$. Samples prepared with weight ratios (i) were activated for 15,30 , 60 and $90 \mathrm{~min}$, and denoted as 15-ANF, 30-ANF, 60-ANF, and 90-ANF, respectively, whereas those prepared with weight ratios (ii) were activated for $15 \mathrm{~min}$, and similarly denoted as 0.01-ANF, 0.03-ANF, and 0.05-ANF.
Furthermore, $0.5 \mathrm{wt} \%$ TEPA solution in absolute ethanol was prepared as an impregnating solution. Then, $100 \mathrm{mg}$ of each sample was added to the solution, and stirred for $6 \mathrm{~h}$ at room temperature. Afterwards, the samples were evaporated to dryness in an oven. However, some of the ANFs were pre-oxidized with $70 \% \mathrm{HNO}_{3}$ solution at $80^{\circ} \mathrm{C}$ for $1 \mathrm{~h}$ before TEPA impregnation. The $\mathrm{HNO}_{3}$ pretreatment was preferably carried out below $100{ }^{\circ} \mathrm{C}$ for no more than $2 \mathrm{~h}$ [12]. Aside from ensuring a complete surface treatment of the fibers, the depth of the ravines increased and the fiber matrix remained uncorroded under those conditions.

\subsection{Characterization of nanofiber adsorbent}

The specific surface area $\left(\mathrm{S}_{\mathrm{BET}}\right)$ and porosity of all the ANFs were measured by $\mathrm{N}_{2}$ adsorption at $77 \mathrm{~K}$ using a surface analyzer (Belsorp mini II, BEL, Tokyo, Japan) at relative pressures $\left(\mathrm{p} / \mathrm{p}_{0}\right)$ of $0-1$. To pre-clean the samples prior to measurement, outgassing under $\mathrm{N}_{2}$ flow for $3 \mathrm{~h}$ at $100{ }^{\circ} \mathrm{C}$ was carried out. The equation based on BET theory (Brunauer-Emmett-Teller) was used to calculate the $\mathrm{S}_{\mathrm{BET}}$, whereas the mesopore volume $\left(\mathrm{V}_{\text {meso }}\right)$ and micropore volume $\left(\mathrm{V}_{\text {micro }}\right)$ were obtained using BarrettJoyner-Halenda (BJH) and MP-plot [5]. The total pore volume $\left(\mathrm{V}_{\text {total }}\right)$ was analyzed at a relative pressure of 0.99 .

The thermal stability of the adsorbents was investigated with the aid of a thermogravimetric analyzer (TGA N-1500, Scinco, USA). Each sample was heated from room temperature to $400{ }^{\circ} \mathrm{C}$ at $10{ }^{\circ} \mathrm{C} / \mathrm{min}$ heating rate under $\mathrm{N}_{2}$ atmosphere. The surface morphology and feature of the samples were observed by field emission scanning electron microscopy (FE-SEM, LEO SUPRA 55 , Germany) with the magnification of $50,000 \times$. It was coupled with an energy-dispersive X-ray spectroscopy (EDS) for simultaneous elemental distribution analysis. In details, the changes in the surface chemical speciation, especially of the nitrogen functional groups, were investigated using X-ray photoelectron spectroscopy (XPS, K-Alpha, Thermo Scientific, USA).

\subsection{Measurement of $\mathrm{CO}_{2}$ adsorption capacity}

The adsorption capacity of the adsorbents for pure $\mathrm{CO}_{2}$ was obtained using a monosorb instrument. The measurement was carried out under pressures ranging from vacuum to ambient (i.e., $\mathrm{p} / \mathrm{p}_{0}=0-1$ ) at $273 \mathrm{~K}$. Furthermore, the selective adsorption capacity for $0.3 \% \mathrm{CO}_{2}$ $\left(99.999 \%\right.$, in binary mixture with $\left.99.99 \% \mathrm{~N}_{2}\right)$ was examined using a lab scale set-up as shown in Fig. 1. The 0.3\% (3000 ppm) $\mathrm{CO}_{2}$ represents the mean concentration of the gas commonly found in indoor spaces [13]. $\mathrm{A} \mathrm{CO}_{2}$ detector (SenseAir, Sweden), equipped with a non-dispersive infrared (NDIR) sensor was used to monitor the $\mathrm{CO}_{2}$ concentration in the exiting gas stream. The same 


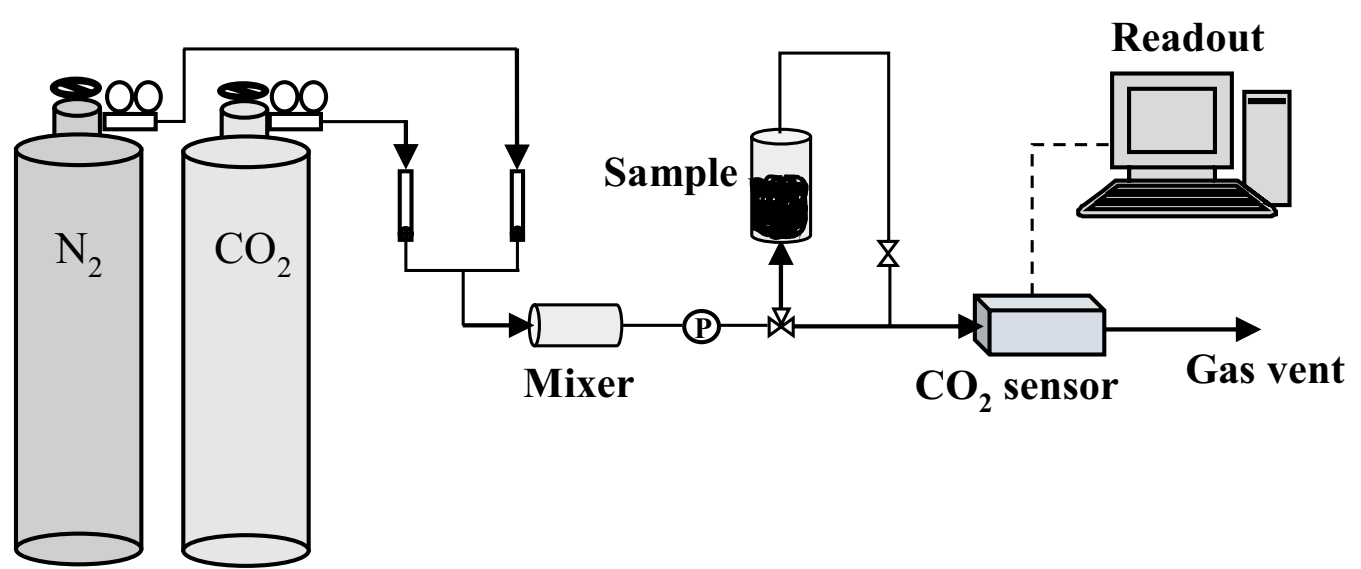

Fig. 1 A schematic diagram of the low-level $\mathrm{CO}_{2}$ adsorption test set-up

set-up was used for adsorption regeneration exercise carried out at $100{ }^{\circ} \mathrm{C}$.

\section{Results and discussion}

\subsection{Physical properties of the ANFs}

Table 1 shows the textural characteristics of all of the ANF samples. We observed that the $S_{B E T}$ and $V_{\text {total }}$ of ANFs were enhanced by either activation time or the quantity of the activation reagent. However, after impregnation with TEPA, the $S_{B E T}$ and $V_{\text {total }}$ were reduced proportionately, an observation that is consistent with those of other studies $[11,14]$. In particular, micropores of the chemically activated ANFs undetectable because the percolation of the TEPA solution blocked the tiny pores. On the contrary, the microporosity of the ANFs derived by physical activation increased after impregnation, probably due to the thermal shrinking of boundary mesopores. Since the kinetic diameter of $\mathrm{CO}_{2}$ is $0.33 \mathrm{~nm}$, a factor that is significant to its physisorption, the proportion of microporosity is essential to the adsorption of the gas. Therefore, we inferred that ANFs prepared by physical activation are more suitable for surface modification by

Table 1 Surface textural and porous properties of all of the ANF samples

\begin{tabular}{|c|c|c|c|c|c|}
\hline Sample & $\mathrm{S}_{\mathrm{BET}}\left(\mathrm{m}^{2} / \mathrm{g}\right)$ & $V_{\text {total }}\left(\mathrm{cm}^{3} / \mathrm{g}\right)$ & $V_{\text {meso }}\left(\mathrm{cm}^{3} / \mathrm{g}\right)$ & $V_{\text {micro }}\left(\mathrm{cm}^{3} / \mathrm{g}\right)$ & $\mathrm{V}_{\text {micro }} / \mathrm{V}_{\text {total }}(\%)$ \\
\hline \multicolumn{6}{|l|}{ Physically activated ANF } \\
\hline 15-ANF & 212.2 & 7.201 & 7.113 & 0.083 & 1.15 \\
\hline 15-ANF-TEPA & 60.98 & 0.490 & 0.487 & 0.010 & 2.04 \\
\hline 30-ANF & 308.4 & 7.882 & 7.802 & 0.137 & 1.74 \\
\hline 30-ANF-TEPA & 100.7 & 0.466 & 0.364 & 0.010 & 2.15 \\
\hline 60-ANF & 673.7 & 15.61 & 15.50 & 0.254 & 1.63 \\
\hline 60-ANF-TEPA & 249.2 & 0.207 & 0.190 & 0.047 & 22.5 \\
\hline $60-\mathrm{ANF}^{-\mathrm{HNO}_{3}}$ & 583.7 & 0.463 & 0.295 & 0.229 & 49.4 \\
\hline 60-ANF-HNO ${ }_{3}$-TEPA & 278.8 & 0.284 & 0.264 & 0.052 & 18.3 \\
\hline 90-ANF & 839.4 & 27.50 & 27.53 & 0.301 & 1.09 \\
\hline 90-ANF-TEPA & 113.0 & 0.246 & 0.170 & 0.015 & 6.01 \\
\hline \multicolumn{6}{|c|}{ Chemically activated ANF } \\
\hline 0.01-ANF & 84.14 & 0.055 & 0.048 & 0.009 & 16.36 \\
\hline 0.01-ANF-TEPA & 26.64 & 0.040 & 0.046 & ND & ND \\
\hline 0.03-ANF & 184.3 & 0.112 & 0.108 & 0.025 & 22.51 \\
\hline 0.03-ANF-TEPA & 65.60 & 0.720 & 0.724 & ND & ND \\
\hline 0.05-ANF & 469.1 & 0.347 & 0.191 & 0.188 & 54.30 \\
\hline 0.05-ANF-TEPA & 50.17 & 1.445 & 1.393 & $N D$ & ND \\
\hline
\end{tabular}

ND not-detected 
alkaline solution impregnation, which would improve the chemisorption of the $\mathrm{CO}_{2}$ molecules.

The $\mathrm{N}_{2}$ adsorption isotherms of a part of physically activated ANFs are compared in Fig. 2. All the isotherms followed a typical behaviour of Type I between 0 and 0.8 of the relative pressure, indicating single-layer reversible adsorption. Type I adsorption frequently occurs on microporous solids. The initial adsorption capacity is relatively large with the change of relative pressure, and then the adsorption capacity will not change greatly with the increase of relative pressure [15]. However, as P/Po approached 1 , the adsorption capacity increased infinitely. This was caused by multiple molecular layers (physisorption) of the sorptive formed at various thicknesses on the solid surface, leading to the formation of Type II adsorption isotherm. Therefore, it can be seen that the ANFs prepared has both inner micropores and outer mesopores well developed.

To further enhance TEPA loading on the ANFs at the same impregnation concentration, the ANFs were oxidized with $70 \% \mathrm{HNO}_{3}$ solution for $1 \mathrm{~h}$ prior to TEPA impregnation. The $\mathrm{HNO}_{3}$ oxidation formed crevasses and pits by eroding the graphene layer primarily from the basal planes of carbonaceous materials [16]. After $\mathrm{HNO}_{3}$ oxidation, the surface became irregular and there were more oxygen-based active groups such as carboxyl, carbonyl and ether groups tethered onto the ANFs [17-19]. The presence of these active groups were advantageous for the attachment of TEPA onto the adsorbent surface via a displacement reaction $[20,21]$.

The optimization of $\mathrm{HNO}_{3}$ pre-oxidation was conducted with 60-ANF because the textural quality $\left(\mathrm{S}_{\mathrm{BET}}\right.$ and $\left.\mathrm{V}_{\text {micro }} / \mathrm{V}_{\text {total }}\right)$ of the 60-ANF-TEPA sample was found best in the TEPA-impregnation step. After pre-oxidation, the $\mathrm{V}_{\text {total }}$ of 60 -ANF decreased significantly from 15.61 to $0.463 \mathrm{~cm}^{3} / \mathrm{g}$. This was a result of mesopore shrinkage, resulting in a large increase in the proportion of micropore volume $\left(\mathrm{V}_{\text {micro }} / \mathrm{V}_{\text {total }}\right)$ from 1.63 to $49.4 \%$. The

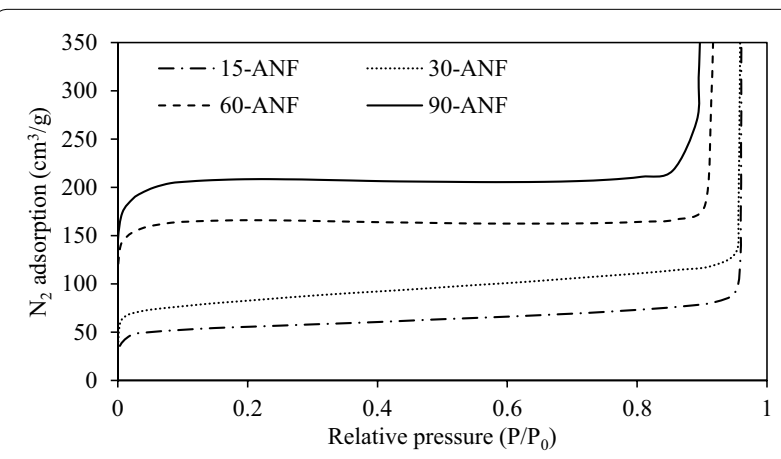

Fig. $2 \mathrm{~N}_{2} / 77 \mathrm{~K}$ isotherm of physically activated ANFs
$\mathrm{V}_{\text {micro }} / \mathrm{V}_{\text {total }}$ has been reported to be the driving force for selective adsorption of $\mathrm{CO}_{2}$ [22]. Despite the significant improvement in this property, a slight decrease in the $\mathrm{S}_{\mathrm{BET}}$ of the $60-\mathrm{ANF}-\mathrm{HNO}_{3}$ sample was observed, which was attributed to the collapse of some mesopores. From the TEPA impregnation results of the adsorbent (before and after oxidation), the pre-treated $60-\mathrm{ANF}^{-} \mathrm{HNO}_{3}$ TEPA sample exhibited superior specific surface area and pore volume. However, the impregnation of TEPA depreciated the microporosity of the adsorbent (from 60-ANF- $\mathrm{HNO}_{3}$ to $60-\mathrm{ANF}-\mathrm{HNO}_{3}$-TEPA), i.e., a much superior microporosity was developed compared to that of 60-ANF. Finally, the pre-oxidized TEPA-doped ANFs showed more superior properties than those that were chemically activated.

The surface morphology of fibers is shown in the FE-SEM micrographs of ANFs (Fig. 3), produced at $50,000 \times$ magnification with $10 \mathrm{kV}$ accelerating voltage. It can be seen that various surface modified ANFs exhibited uniform size distribution of fiber thickness. However, there were obvious etching on the surface of the TEPAmodified ANFs (Fig. 3b, d), while those of 60-ANF-TEPA sample (Fig. 3b) was deformed. Generally, the structural effects of $\mathrm{HNO}_{3}$ pre-oxidation on the ANFs correspond with the differences in the $S_{B E T}$ and $V_{\text {total }}$ of 60-ANF$\mathrm{HNO}_{3}$, which were higher than those of 60-ANF-TEPA and 60-ANF- $\mathrm{HNO}_{3}$-TEPA (Table 1).

To understand the thermal stability of modified ANFs, we performed a thermogravimetric analysis on the samples. The thermograms obtained are shown in Fig. 4. All of the samples showed different rates of weight loss as the volatile organics and moisture content were eluted below $100{ }^{\circ} \mathrm{C}$. TEPA-treated samples evinced a less steep slope than those that were untreated, indicating more refractiveness of the contents introduced by TEPA treatment. Between 100 and $400{ }^{\circ} \mathrm{C}$, the 60-ANF sample showed the most impressive thermal stability, as a steady plateau was observed. Such steadiness could be attributed to the homogeneity of the fibers, devoid of foreign dopants in the matrix as can be seen in Fig. 3a. However, the thermogram of pre-oxidized fibers exhibited steeper depreciation because the oxidized fiber surfaces were more easily decomposed under an increasing temperature [20]. The strong acidic functionalities such as carboxylic, anhydrides and lactones tend to be decomposed at low temperatures, while the weak acidic functionalities such as carbonyl, phenol and quinone are dissipated at high temperature $[23,24]$. The steady weight loss of TEPA impregnated samples (60-ANF-TEPA and 60-ANF$\mathrm{HNO}_{3}$-TEPA) began at about $180^{\circ} \mathrm{C}$. From the difference in their thermograms, we inferred that chemical modification was most pronounced on the surface of the preoxidized 60-ANF- $\mathrm{HNO}_{3}$-TEPA sample. 

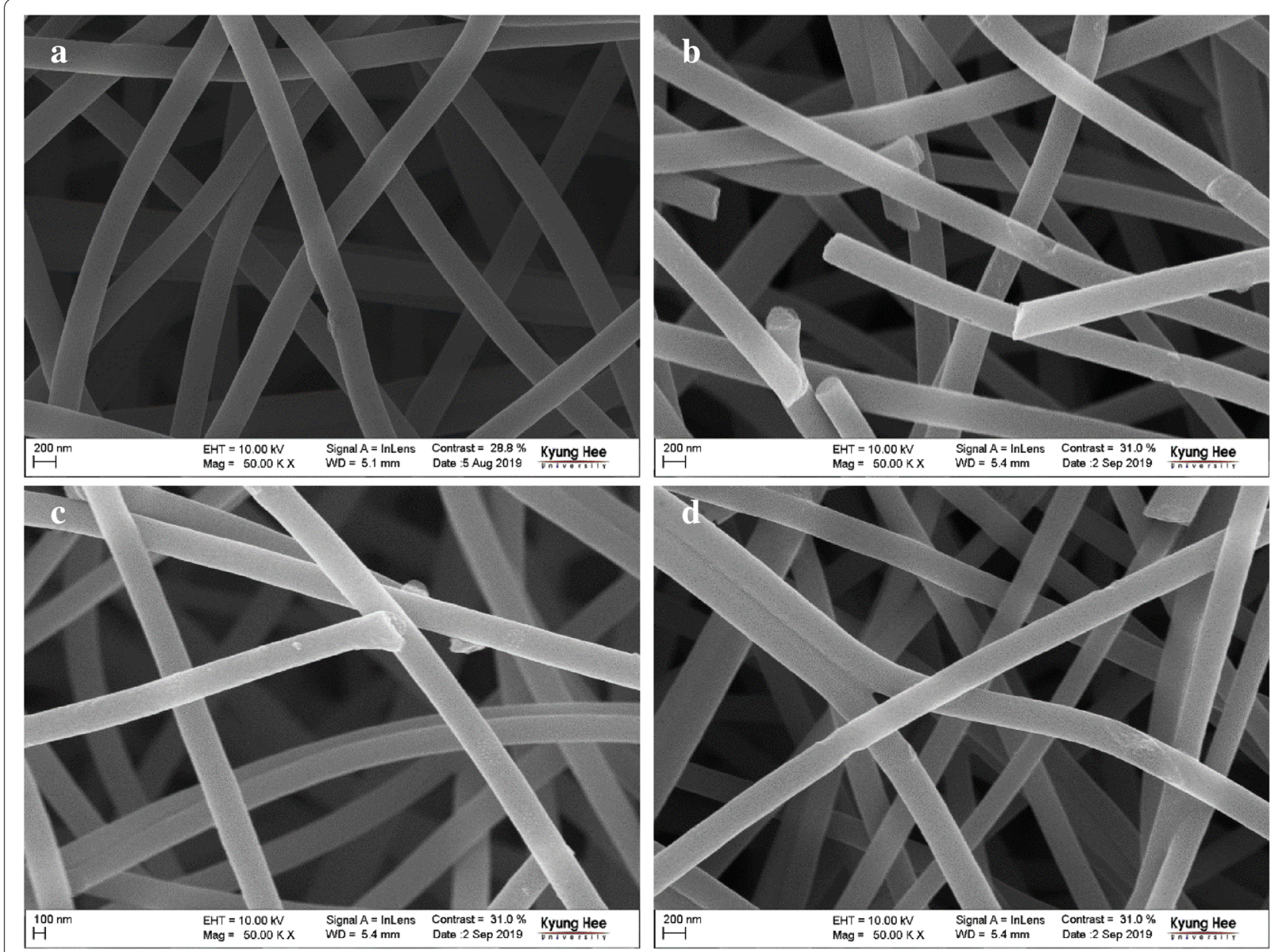

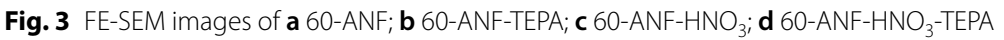

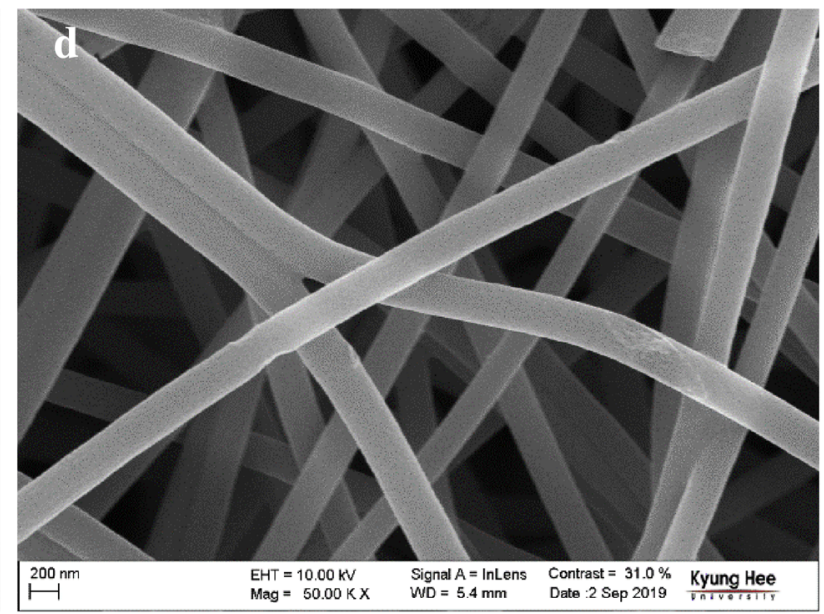

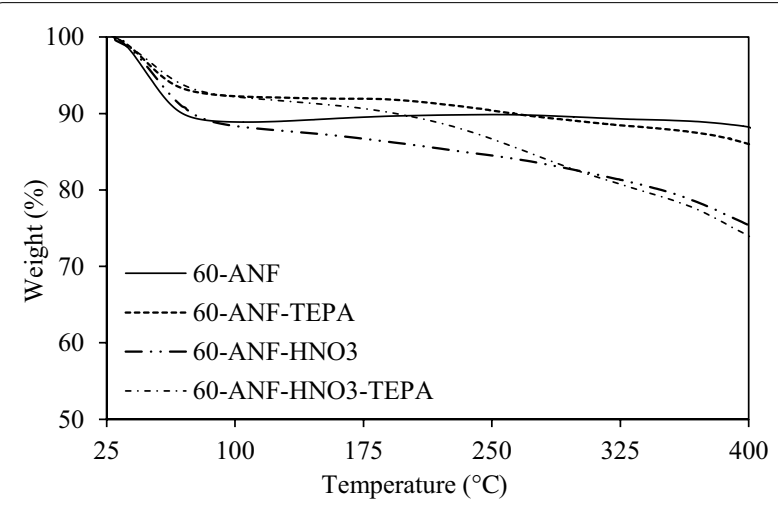

Fig. 4 Thermograms showing slopes that are indicative of the thermal stability of ANFs

\subsection{Chemical properties of the ANFs}

Through high resolution XPS analysis of the samples, the major peaks of the scan spectra determined to be
Table 2 The XPS-derived elemental compositions and atomic ratios of 60 -ANF-based samples

\begin{tabular}{|c|c|c|c|c|c|}
\hline \multirow[t]{2}{*}{ Element (\%) } & \multicolumn{3}{|c|}{$\begin{array}{l}\text { Elementary composition } \\
(\%)\end{array}$} & \multicolumn{2}{|c|}{ Atomic ratio (\%) } \\
\hline & $C_{1 s}$ & $\mathrm{O}_{1 \mathrm{~s}}$ & $\mathrm{~N}_{1 \mathrm{~s}}$ & $\mathrm{O}_{1 \mathrm{~s}} / \mathrm{C}_{1 \mathrm{~s}}$ & $\mathrm{~N}_{1 s} / \mathrm{C}_{1 \mathrm{~s}}$ \\
\hline 60-ANF & 89.02 & 5.16 & 5.82 & 5.80 & 6.54 \\
\hline 60-ANF-TEPA & 84.20 & 5.01 & 10.79 & 5.95 & 12.81 \\
\hline 60-ANF- $\mathrm{HNO}_{3}$ & 81.50 & 12.02 & 6.48 & 14.75 & 7.95 \\
\hline 60-ANF-HNO ${ }_{3}$-TEPA & 77.41 & 9.28 & 13.31 & 11.99 & 17.19 \\
\hline
\end{tabular}

due to the $\mathrm{C}_{1 \mathrm{~s}}, \mathrm{O}_{1 \mathrm{~s}}$, and $\mathrm{N}_{1 \mathrm{~s}}$ photoelectrons. Table 2 lists the surface elemental compositions and atomic ratios of optimized 60-ANF samples. As expected, the $\mathrm{HNO}_{3}$ treated sample (60-ANF- $\left.\mathrm{HNO}_{3}\right)$ showed higher $\mathrm{O}_{1 \mathrm{~s}} /$ $\mathrm{C}_{1 \mathrm{~s}}$ ratios $(14.75 \%)$ and $\mathrm{N}_{1 \mathrm{~s}} / \mathrm{C}_{1 \mathrm{~s}}$ ratios $(7.95 \%)$ than the unoxidized precursor (60-ANF). With $\mathrm{HNO}_{3}$ treatment, the amount of $\mathrm{O}_{1 \mathrm{~s}}$ and $\mathrm{N}_{1 \mathrm{~s}}$ increased significantly, while 
the proportion of $\mathrm{C}_{1 \mathrm{~s}}$ decreased due to surface eroding of the graphene layers, attributed to wet oxidation [25]. With the same impregnant concentration, the oxidized 60-ANF- $\mathrm{HNO}_{3}$-TEPA sample showed a higher $\mathrm{N}_{1 \mathrm{~s}} / \mathrm{C}_{1 \mathrm{~s}}$ ratios $(17.19 \%)$ than that of the 60-ANF-TEPA (12.81\%) sample, indicating that the $\mathrm{HNO}_{3}$ oxidation treatment improved the loading of TEPA.

To better understand the chemical speciation of $\mathrm{C}$ and $\mathrm{N}$ on the selected samples, deconvolution of the XPS spectra was performed in the $C_{1 s}$ and $N_{1 s}$ regions. Figure 5 shows the best curve fit for the high resolution XPS $C_{1 \mathrm{~s}}$ spectra of all of the samples. Table 3 provides the percentage composition of the functional groups in the $\mathrm{C}_{1 \mathrm{~s}}$ regime as (i.e. $\mathrm{C}$ in polyaromatic structures $\left(\mathrm{C}\left(\mathrm{sp}^{2}\right), \mathrm{BE}=284.6 \mathrm{eV}\right)$ or aliphatic structures $\left(\mathrm{C}\left(\mathrm{sp}^{3}\right)\right.$, $\mathrm{BE}=285.4 \mathrm{eV})$ : in phenolic, alcohol, ether or $\mathrm{C}=\mathrm{N}$ groups $(\mathrm{BE}=286.0 \mathrm{eV})$ : in carbonyl or quinone groups $(\mathrm{BE}=287.6 \mathrm{eV})$ : and in carboxyl, lactone, or ester groups $(\mathrm{BE}=288.8 \mathrm{eV})$ [26]. With either $\mathrm{HNO}_{3}$ or TEPA treatment, the appearance of $-\mathrm{OH}$ and $\mathrm{C}=\mathrm{O}$ groups on the fiber surface resulted in a decrease in the relative proportion of $\mathrm{C}\left(\mathrm{sp}^{2}\right)$ and $\mathrm{C}\left(\mathrm{sp}^{3}\right)$. Wet oxidation often incorporates high amount of oxygen, as carboxylic and phenolic functionalities on the carbon surface [20]. As expected, upon $\mathrm{HNO}_{3}$ oxidation (60-ANF- $\mathrm{HNO}_{3}$ ), the amount of $-\mathrm{COOH}$ groups increased significantly. However, the content of $-\mathrm{COOH}$ groups in the TEPA impregnated
Table 3 Quantitative results of the fits of the XPS $C_{1 s}$ region, given in $\%$ of total intensity

\begin{tabular}{|c|c|c|c|c|c|}
\hline Sample & $\begin{array}{l}286.4 \\
C\left(s^{2}\right)\end{array}$ & $\begin{array}{l}285.4 \\
C\left(\mathrm{sp}^{3}\right)\end{array}$ & $\begin{array}{l}286.0 \\
-\mathrm{OH}\end{array}$ & $\begin{array}{l}287.6 \\
C=0\end{array}$ & $\begin{array}{l}288.8 \\
-\mathrm{COOH}\end{array}$ \\
\hline 60-ANF & 71.64 & 26.56 & - & - & 1.80 \\
\hline 60-ANF-TEPA & 58.31 & 24.03 & 10.37 & 5.89 & 1.40 \\
\hline $60-\mathrm{ANF}-\mathrm{HNO}_{3}$ & 59.74 & 13.52 & 13.54 & 7.90 & 5.30 \\
\hline 60-ANF-HNO ${ }_{3}$-TEPA & 49.61 & 22.58 & 15.43 & 9.94 & 2.43 \\
\hline
\end{tabular}

60-ANF-TEPA and 60-ANF- $\mathrm{HNO}_{3}$-TEPA samples decreased by $0.4 \%$ and $2.87 \%$ respectively, compared to that of 60 -ANF and 60-ANF- $\mathrm{HNO}_{3}$. Of the two possible types of acidic reactive groups present on the surface (phenolic $-\mathrm{OH}$ and carboxylic $-\mathrm{COOH}$ ), only the carboxyl groups could undergo a reaction with TEPA because both phenolic and aliphatic hydroxyl groups are essentially inert toward primary and secondary amino groups [27]. This result indicated the successful substitution reaction of the acidic oxygen functionalities by the $\mathrm{N}$-bearing groups from TEPA.

The nature and amount of the $\mathrm{N}$ species tethered by the amination were investigated. Figure 6 shows the best curve fit for the high resolution XPS $N_{1 s}$ spectra of all samples, while Table 4 lists the percentage of nitrogen-containing functional groups. The primary surface nitrogen groups found on the ANFs
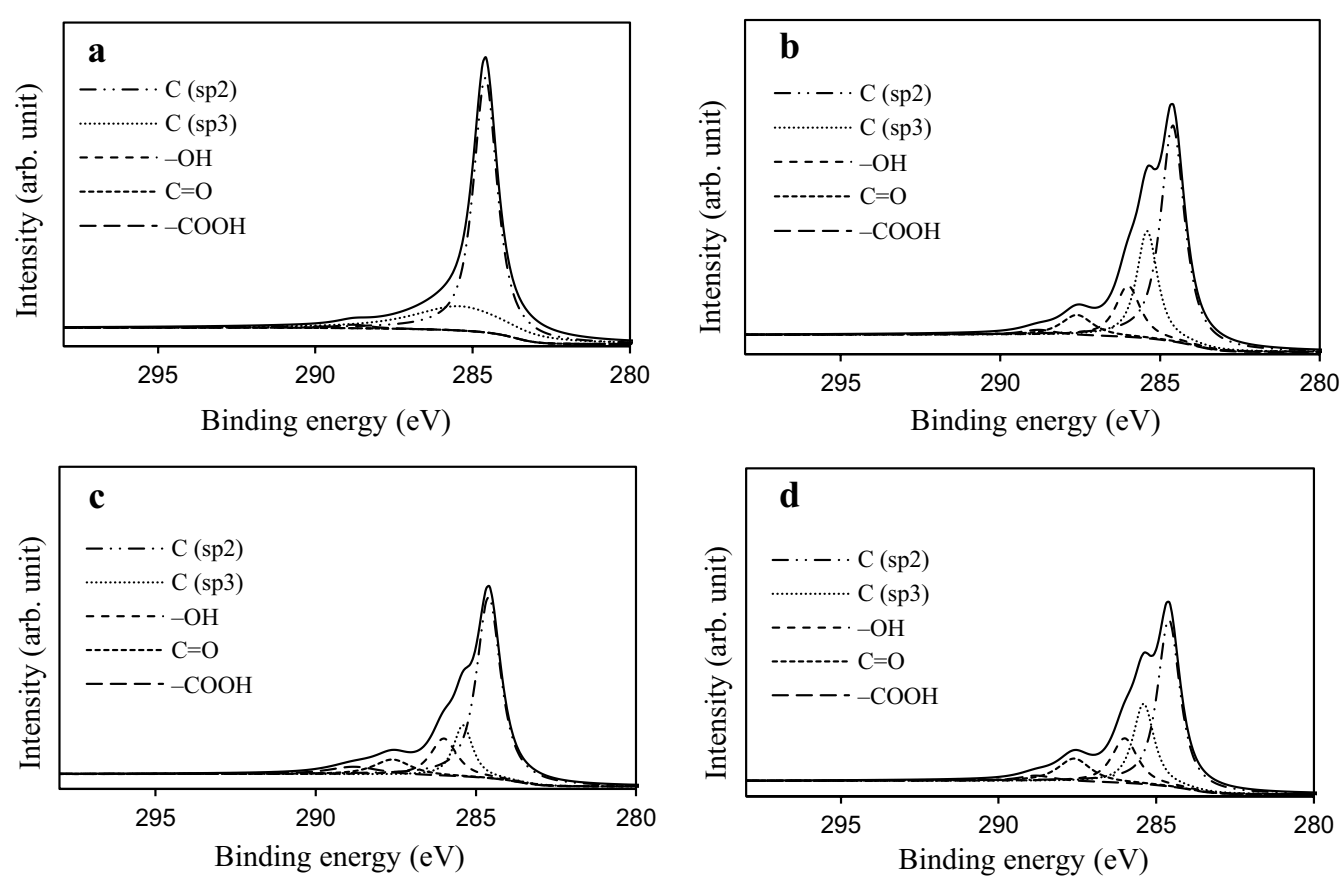

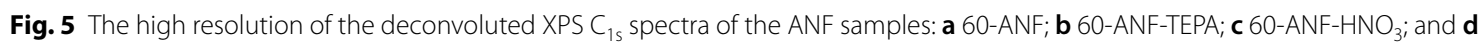
60-ANF- $\mathrm{HNO}_{3}$-TEPA 

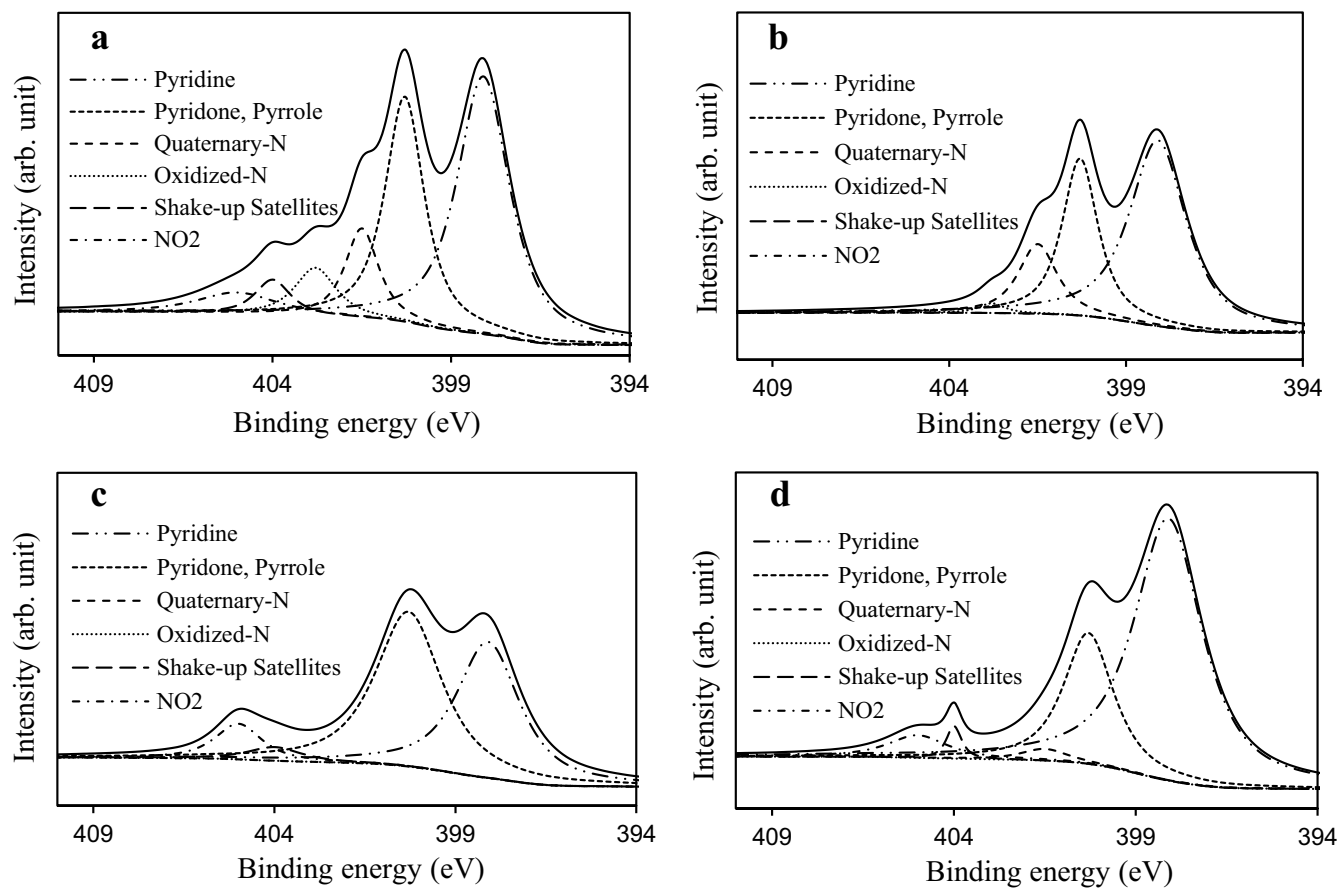

Fig. 6 The high resolution of deconvoluted XPS $N_{1 s}$ spectra of the ANF samples: a 60-ANF; b 60-ANF-TEPA; c $60-A N F-H N O_{3}$; and $\mathbf{d}$ $60-\mathrm{ANF}-\mathrm{HNO}_{3}$-TEPA

Table 4 Quantitative results of the deconvoluted XPS $\mathrm{N}_{1 \mathrm{~s}}$ spectra values given in \% of total intensity

\begin{tabular}{|c|c|c|c|c|c|c|}
\hline Sample & $\begin{array}{l}398.1 \mathrm{eV} \\
\text { Pyridine }\end{array}$ & $\begin{array}{l}400.3 \text { eV Pyridone, } \\
\text { Pyrrole }\end{array}$ & $\begin{array}{l}401.5 \mathrm{eV} \\
\text { Quaternary-N }\end{array}$ & $\begin{array}{l}402.8 \mathrm{eV} \\
\text { Oxidized-N }\end{array}$ & $\begin{array}{l}404 \mathrm{eV} \text { Shake-up } \\
\text { satellites }\end{array}$ & $405 \mathrm{eV} \mathrm{NO}$ \\
\hline 60-ANF & 44.98 & 29.07 & 9.84 & 6.54 & 4.03 & 5.54 \\
\hline 60-ANF-TEPA & 55.48 & 29.30 & 13.92 & 1.30 & - & - \\
\hline $60-\mathrm{ANF}^{-\mathrm{HNO}_{3}}$ & 40.38 & 48.34 & - & - & 3.46 & 7.82 \\
\hline 60-ANF-HNO ${ }_{3}$-TEPA & 66.88 & 24.25 & 2.02 & - & 1.86 & 4.99 \\
\hline
\end{tabular}

were pyridine-type $(\mathrm{BE}=398.1 \mathrm{eV})$, pyridone and pyrrole $(\mathrm{BE}=400.3 \mathrm{eV})$, quaternary- $\mathrm{N}(\mathrm{BE}=401.5 \mathrm{eV})$, oxidized-N $(\mathrm{BE}=402.8 \mathrm{eV})[28]$, and chemisorption of $\mathrm{NO}_{2}$ at $405 \mathrm{eV}$ [14]. Pyridinic and pyridine/pyrrole $\mathrm{N}$ were the two dominant N-groups found on the 60-ANF. Both accounted for about $74 \%$ of the total $\mathrm{N}$, while the other groups were present in minor to trace quantities. However, upon the impregnation of TEPA (60-ANF-TEPA), there was a significant increase in the pyridinic and quaternary $\mathrm{N}$-groups, possibly derived from the total conversion of shake-up satellites and adsorbed $\mathrm{NO}_{2}$. Such observation which implied that the linear TEPA resulted in the increase of pyridine-like structures or six-member or five-member rings [14]. As expected, $\mathrm{HNO}_{3}$ oxidation evinced lowering of basic $\mathrm{N}$-groups (pyridines), while the least basic groups (shake-up satellites and adsorbed
$\mathrm{NO}_{2}$ ) were re-introduced to the ANFs. Furthermore, final TEPA amination of the pre-oxidized samples (60-ANF$\mathrm{HNO}_{3}$-TEPA) ensured that the quantity of the desired pyridinic $\mathrm{N}$ was optimized, while the unwanted shakeup satellites and adsorbed $\mathrm{NO}_{2}$ groups were significantly lowered. We concluded that although TEPA is a viable amination agent, it also incorporates refractory quaternary- $\mathrm{N}$ while expunging unwanted $\mathrm{N}$ groups. In addition, $\mathrm{HNO}_{3}$ was confirmed as an excellent pre-oxidant for TEPA amination of ANFs, as it improved the tethering of preferred pyridine groups which are favorable for selective adsorption of $\mathrm{CO}_{2}$ over $\mathrm{N}_{2}$ [29].

To complement the elemental distribution analysis carried out with the XPS, an EDS analysis was performed on the optimized sample (60-ANF- $\mathrm{HNO}_{3}$-TEPA). As shown in the Fig. 7, the EDS spectrum identified only a trace amount of $\mathrm{N}$ on the sample surface. Also, finite but 


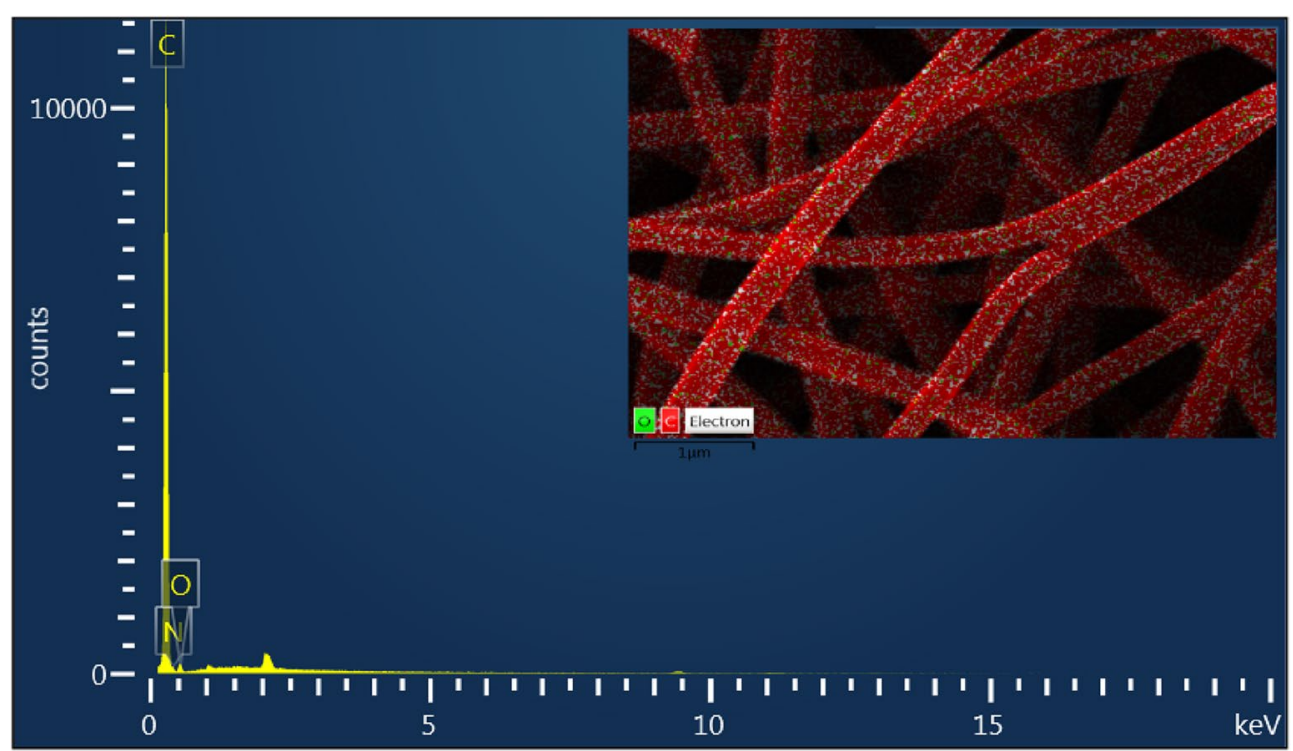

Fig. 7 The EDS spectrum of the sample 60-ANF-HNO3-TEPA (inset: EDS layered image)

uniform distribution of carbon and oxygen was observed. This was because XPS analysis is more sensitive than EDS, with a minimum detection concentration of $0.1 \%$, although at the analysis depth of 10-20 nm only, while EDS analysis occurs bulk measurement that reaches micron level [30, 31]. Since the impregnated N-groups were populated on the surface of the adsorbent, the EDS analysis could only detect a lesser percentage compared to those of the XPS. Still, both measurements give comparatively similar results when compared in proportion.

\section{Adsorption and regeneration of nanofiber adsorbents}

4.1 $\mathrm{CO}_{2}$ adsorption capacities of the ANFs

Table 5 shows the adsorption capacities for $0.3 \%$ and $100 \% \mathrm{CO}_{2}$ of all the test samples. We found that with either an increase in the activation time or the quantity of the activation reagent, the $\mathrm{CO}_{2}$ adsorption capacity increased for both levels. This result is fundamentally true because gas adsorption is positively correlated with both the specific surface area and microporosity [32]. Although the $S_{B E T}$ of chemically activated ANFs was smaller than that of physically activated ANFs, the adsorption capacities of the former for pure $\mathrm{CO}_{2}$ were still significantly improved. In regards to the $0.3 \% \mathrm{CO}_{2}$ test feed (Table 5), physically activated ANFs exhibited significantly higher adsorption capacities than their counterparts. We ascribed this result to the larger specific surface area induced by physical activation, which, in turn, favored TEPA impregnation and eventually $\mathrm{CO}_{2}$ cap-

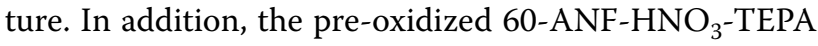

Table $5 \mathrm{CO}_{2}$ adsorption capacities (q) of all ANF samples prepared in this work

\begin{tabular}{|c|c|c|}
\hline \multirow[t]{2}{*}{ Sample } & \multicolumn{2}{|c|}{$\mathrm{CO}_{2}$ adsorption $(\mathrm{mmol} / \mathrm{g})$} \\
\hline & $0.3 \%$ & $100 \%$ \\
\hline \multicolumn{3}{|c|}{ Physically activated ANF } \\
\hline 15-ANF & 0.107 & 1.89 \\
\hline 15-ANF-TEPA & 0.034 & 0.65 \\
\hline 30-ANF & 0.151 & 2.10 \\
\hline 30-ANF-TEPA & 0.119 & 0.97 \\
\hline 60-ANF & 0.203 & 2.84 \\
\hline 60-ANF-TEPA & 0.087 & 1.48 \\
\hline $60-\mathrm{ANF}^{-}-\mathrm{HNO}_{3}$ & 0.121 & 1.98 \\
\hline 60-ANF-HNO ${ }_{3}$-TEPA & 0.334 & 2.96 \\
\hline 90-ANF & 0.238 & 2.80 \\
\hline 90-ANF-TEPA & 0.117 & 1.00 \\
\hline \multicolumn{3}{|c|}{ Chemically activated ANF } \\
\hline 0.01-ANF & 0.021 & 1.96 \\
\hline 0.01-ANF-TEPA & 0.015 & 0.33 \\
\hline 0.03-ANF & 0.028 & 2.67 \\
\hline 0.03-ANF-TEPA & 0.013 & 0.64 \\
\hline 0.05-ANF & 0.096 & 2.68 \\
\hline 0.05-ANF-TEPA & 0.020 & 0.41 \\
\hline
\end{tabular}

sample had higher amino loading (Table 2 and Fig. 4), resulting in the adsorption of $0.3 \% \mathrm{CO}_{2}$, which was about quadruple that of not pre-oxidized 60-ANF-TEPA.

Table 6 shows a comparison list of the $\mathrm{CO}_{2}$ adsorption capacities of various adsorbents from open literatures. 
Table 6 Comparison of the $\mathrm{CO}_{2}$ adsorption capacities $(q)$ of the current work with those from literature

\begin{tabular}{|c|c|c|c|c|c|c|}
\hline Support & Modification chemicals & $\mathrm{S}_{\mathrm{BET}}\left(\mathrm{m}^{2} / \mathrm{g}\right)$ & $\mathrm{V}_{\text {micro }} / \mathrm{V}_{\text {total }}(\%)$ & $\mathrm{CO}_{2}$ feed level & $\begin{array}{l}\mathrm{CO}_{2} \text { adsorption } \\
(\mathrm{mmol} / \mathrm{g})\end{array}$ & References \\
\hline \multirow[t]{2}{*}{ ANF } & - & 300 & 48 & $100 \%$ & 2.74 & [33] \\
\hline & Urea 1:4 & 542 & 92 & $100 \%$ & 2.98 & [34] \\
\hline Commercial ACF & $10 w t \%$ TEPA & 1051 & 73 & $15 \%$ & 0.50 & [14] \\
\hline CNTs & APTS & 15.87 & 53 & $15 \%$ & 0.98 & [35] \\
\hline ACF & $\mathrm{HN}_{3}$ gas & 1293 & 85 & $0.3 \%$ & 0.40 & {$[36]$} \\
\hline \multirow[t]{2}{*}{$A C$} & $\mathrm{HN}_{3}$ gas & 1251 & - & $10 \%$ & 0.63 & {$[37]$} \\
\hline & & & & $0.3 \%$ & 0.15 & \\
\hline \multirow[t]{2}{*}{ ANF } & $0.5 \mathrm{wt} \% \mathrm{TEPA}$ & 278.8 & 18.3 & $0.3 \%$ & 0.33 & This work \\
\hline & & & & $100 \%$ & 2.96 & \\
\hline
\end{tabular}

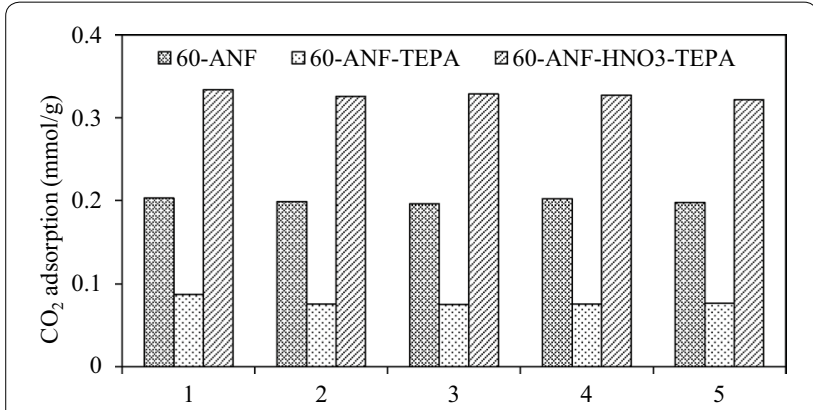

Fig. 8 Adsorption capacity of carbon dioxide in five cycles

For all the sorbents, the higher $\mathrm{S}_{\mathrm{BET}}$ and $\mathrm{V}_{\text {micro }} / \mathrm{V}_{\text {total }}$ were, the higher the adsorption capacity of pure $\mathrm{CO}_{2}$ was. In our study, an increase in amino group content on the surface of the modified samples also led to a relatively high $\mathrm{CO}_{2}$ adsorption capacity. However, as most published works have focused on pure and flue gas $\mathrm{CO}_{2}$ levels, our work is unique in that we attempted to improve the $\mathrm{CO}_{2}$ adsorption selectivity from indoor low levels.

\subsection{Regeneration capacity of the ANFs}

The regeneration of our representative samples for each treatment were examined by a simple temperature programmed desorption (TPD) using the TGA. The desorption temperature was set at $100{ }^{\circ} \mathrm{C}$ under $\mathrm{N}_{2}$ atmosphere. It has been confirmed that the desorption of $\mathrm{CO}_{2}$ form $\mathrm{CO}_{2}$-TEPA interaction is likely occurred in two stages: (i) slow transport via the decomposition of primary ammonium-carbamate species, followed by (ii) rapid desorption of primary and secondary ammonium-carbamate species at $100{ }^{\circ} \mathrm{C}$. At $100{ }^{\circ} \mathrm{C}$, the ammonium-carbamate species was eliminated, which liberated most of the adsorbed $\mathrm{CO}_{2}$ [38]. Figure 8 shows the 5-cycle regeneration adsorptions of $\mathrm{CO}_{2}(3000 \mathrm{ppm})$. Quantitatively, the adsorption capacity of sample 60-ANF, 60-ANF-TEPA and $60-\mathrm{ANF}-\mathrm{HNO}_{3}$-TEPA decreased mildly by $2.62 \%$,
$11.49 \%$ and $3.58 \%$ respectively, after 5 cycles. The regeneration performance of the TEPA impregnated samples was relatively weak, which may be caused by the thermal-induced elution of some TEPA molecules from the surface.

\section{Conclusions}

Nanofibers were prepared by electrospinning before physical or chemical activation to obtain activated nanofibers (ANFs) with varying structural and chemical characteristics. All of the ANFs were impregnated with a TEPA solution of varying amounts. By examination, we found that the ANFs that were physically activated were more suitable for TEPA impregnation because of the enhanced specific surface area and porosity. After TEPA impregnation, the specific surface area and total pore volume of the adsorbents decreased significantly. After the $\mathrm{HNO}_{3}$ pre-oxidation treatment, the amine loading improved the incorporation of useful, basic pyridinic nitrogen, whereas the least basic $\mathrm{N}$ functionalities were effectively removed or converted. Therefore, the adsorption capacity of the optimized 60-ANF- $\mathrm{HNO}_{3}$-TEPA for $0.3 \%$ and $100 \% \mathrm{CO}_{2}$ increased from 0.12 and $1.89 \mathrm{mmol} / \mathrm{g}$ (by 60-ANF-TEPA) to 0.33 and $2.96 \mathrm{mmol} / \mathrm{g}$, respectively. A 5-cycle regeneration test showed a relatively stable adsorption of thermally refreshed adsorbents for proficient reusability. Consequently, $\mathrm{HNO}_{3}$ pre-oxidation of TEPA-doped ANF is efficient for enhancing low-level $\mathrm{CO}_{2}$ adsorption from indoor spaces.

\section{Abbreviations}

ANF: activated carbon nanofiber; TEPA: tetraethylenepentamine; EPA: Environmental Protection Agency; IAQ: indoor air quality; PAN: polyacrylonitrile; DMF: N,N-dimethylformamide; FE-SEM: field emission scanning electron microscopy; XPS: X-ray photoelectron spectroscopy; EDS: energy-dispersive X-ray spectroscopy; NDIR: non-dispersive infrared; ND: not-detected; IUPAC: International Union of Pure and Applied Chemistry; BE: binding energy; APTS: 3-aminopropyl-triethoxysilane; TPD: simple temperature programmed desorption. 


\section{Acknowledgements}

This work was supported by the National Research Foundation of Korea (NRF) grant funded by the Korea government (MSIT, MOE) and (No. 2019M3E7A1113077).

\section{Authors' contributions}

JW completed the literature review, main experimental works and wrote the manuscript. AAA and JMO reviewed and edited the article, and YMJ designed the entire study including funding. All authors read and approved the final manuscript.

\section{Funding}

This work was supported by the Basic Science Research Program through the National Research Foundation of Korea (NRF) funded by the Korea government (MSIT, MOE) and (No. 2019M3E7A1113077).

\section{Availability of data and materials}

Not applicable.

\section{Competing interests}

The authors declare that they have no competing interests.

\section{Author details}

${ }^{1}$ Department of Applied Environmental Science, Kyung Hee University, 1732, Deogyeong-daero, Giheung-gu, Yogin-si, Gyeonggi-do 17103, Republic of Korea. ${ }^{2}$ Centre for Renewable Energy Technology (CRET), The Federal University of Technology, P.M.B. 704, Akure, Nigeria.

Received: 9 October 2019 Accepted: 6 January 2020

Published online: 17 February 2020

\section{References}

1. Airqualitynews, $\mathrm{CO}_{2}$ affects human health at lower levels than previously thought (2019). https://airqualitynews.com/2019/07/10/co2-affectshuman-health-at-lower-levels-than-previously-thought.

2. R. Serna-Guerrero, A. Sayari, Modeling adsorption of $\mathrm{CO}_{2}$ on amine-functionalized mesoporous silica. 2: kinetics and breakthrough curves. Chem. Eng. J. 161, 182-190 https://doi.org/10.1016/j.cej.2010.04.042.

3. S.M. Saad, A.Y.M. Shakaff, A.R.M. Saad, A.M. Yusof, A.M. Andrew, A .Zakaria, A.H. Adom, Development of indoor environmental index: air quality index and thermal comfort index. AIP Conf. Proc. 1808, 020043 (2017). https://doi.org/10.1063/1.4975276

4. N.Diez, P.Alvarez, M.Granda, C.Blanco, R.Santamaria, R.Menendez, $\mathrm{CO}_{2}$ adsorption capacity and kinetics in nitrogen-enriched activated carbon fibers prepared by different methods. Chem. Eng. J. 281, 704-712 (2015). https://doi.org/10.1016/j.cej.2015.06.126

5. Q.Ye, J.Q.Jiang, C.X. Wang, Y.M. Liu, H.Pan, Y.Shi, Adsorption of lowconcentration carbon dioxide on amine-modified carbon nanotubes at ambient temperature. Energy Fuels. 26, 2497-2504 (2012). https://doi. org/10.1021/ef201699w

6. P.J.E. Harlick, A.Sayari, Applications of pore-expanded mesoporous silicas. 3: Triamine silane grafting for enhanced $\mathrm{CO}_{2}$ adsorption. Ind. Eng. Chem. Res. 45, 3248-3255 (2006). https://doi.org/10.1021/ie051286p

7. J.Fujiki, K.Yogo, Carbon dioxide adsorption onto polyethylenimine-functionalized porous chitosan beads. Energy Fuels 28, 6467- 6474 (2014). https://doi.org/10.1021/ef500975g

8. N. Chouikhi, J.A. Cecilia, E. Vilarrasa-García, S. Besghaier, M. Chlendi, F...F. Duro, E.R. Castellon, M. Bagane, $\mathrm{CO}_{2}$ adsorption of materials synthesized from clay minerals: a review. Minerals 9, 514 (2019). https://doi. org/10.3390/min9090514

9. N. Rao, M. Wang, Z.M. Shang, Y.W. Hou, G.Z. Fan, J.F. Li, CO 2 adsorption by amine-functionalized MCM-41: a comparison between impregnation and grafting modification methods. Energy Fuels 32, 670-677 (2018). https:// doi.org/10.1021/acs.energyfuels.7b02906

10. M.G. Plaza, C. Pevida, A. Arenillas, F. Rubiera, J.J. Pis, $\mathrm{CO}_{2}$ capture by adsorption with nitrogen enriched carbons. Fuel 86, 2204-2212 (2007). https://doi.org/10.1016/j.fuel.2007.06.001

11. J. Jiao, J. Cao, Y. Xia, L.Z. Zhao, Improvement of adsorbent materials for $\mathrm{CO}_{2}$ capture by amine functionalized mesoporous silica with worm-hole framework structure. Chem. Eng. J. 306, 9-16 (2016). https://doi. org/10.1016/j.cej.2016.07.041

12. J. Yang, L.X. Zhang, L. Zhou, X.J. Gong, Surface treatment of carbon fiber with nitric acid. Contemp. Chem. Ind. 44, 2289-2293 (2015). https://doi org/10.3969/j.issn.1671-0460.2015.10.005

13. A.A. Adelodun, J.C. Ngila, D.G. Kim, Y.M. Jo, Isotherm, thermodynamic and kinetic studies of selective $\mathrm{CO}_{2}$ adsorption on chemically modified carbon surfaces. Aerosol Air Qual. Res. 16, 3312-3329 (2016). https://doi. org/10.4209/aaqr.2016.01.0014

14. Y.C. Chiang, Y.J. Chen, C.Y. Wu, Effect of relative humidity on adsorption breakthrough of $\mathrm{CO}_{2}$ on activated carbon fibers. Materials $\mathbf{1 0}, 1296$ (2017). https://doi.org/10.3390/ma10111296

15. A.R. Barron, Physical methods in chemistry and nano science (cnx. org, 2012), p. 189-190.

16. C.U. Pittman Jr., G.R. He, B. Wu, S.D. Gardner, Chemical modification of carbon fiber surfaces by nitric acid oxidation followed by reaction with tetraethylenepentamine. Carbon 35, 317-331 (1997). https://doi. org/10.1016/S0008-6223(97)89608-X

17. Y. Han, R. Li, C. Brückner, T.M. Vadas, Controlling the surface oxygen groups of polyacrylonitrile-based carbon nanofiber membranes while limiting fiber degradation. C J. Carbon Res. 4, 40 (2018). https://doi. org/10.3390/c4030040

18. S. Tiwari, J. Bijwe, S. Panier, Tribological studies on polyetherimide composites based on carbon fabric with optimized oxidation treatment. Wear 271, 2252-2260 (2011). https://doi.org/10.1016/j.wear.2010.11.052

19. L. Mahardiani, S. Saputro, F. Baskoro, N.M. Zinki, M. Taufiq, Facile synthesis of carboxylated activated carbon using green approach for water treatment. Mater. Sci. Eng. 578, 012003 (2019). https://doi.org/10.1088/1757899X/578/1/012003

20. M.S. Shafeeyan, W.M.A. Wan Daud, A. Houshmand, A. Shamiri, A review on surface modification of activated carbon for carbon dioxide adsorption. J. Anal. Appl. Pyrolysis. 89, 143-151 (2010). https://doi.org/10.1016/j. jaap.2010.07.006

21. A.A. Adelodun, Y.H. Lim, Y.M. Jo, Effect of UV-C on pre-oxidation prior amination for preparation of a selective $\mathrm{CO}_{2}$ adsorbent. J Anal. Appl. Pyrolysis 105, 191-198 (2014). https://doi.org/10.1016/j.jaap.2013.11.004

22. M.S. Shafeeyan, W.M.A. WanDaud, A. Houshmand, A. Arami-Niya, Ammonia modification of activated carbon to enhance carbon dioxide adsorption: effect of pre-oxidation. Appl. Surf. Sci. 257, 3936-3942 (2010). 10.1016/j.apsusc.2010.11.127.

23. J.L. Figueiredo, M.F.R. Pereira, M.M.A. Freitas, J.J.M. Orfao, Modification of the surface chemistry of activated carbons. Carbon 37, 1379-1389 (1999). https://doi.org/10.1016/S0008-6223(98)00333-9

24. J.L. Figueiredo, M.F.R. Pereira, M.M.A. Freitas, J.J.M. Órfão, Characterization of active sites on carbon catalysts. Ind. Eng. Chem. Res. 46, 4110-4115 (2007). https://doi.org/10.1021/ie061071v

25. B. Huang, G.W. Liu, P.H. Wang, X. Zhao, H.X. Xu, Effect of nitric acid modification on characteristics and adsorption properties of lignite. Processes 7, 167 (2019). https://doi.org/10.3390/pr7030167

26. Y.C. Chiang, W.H. Lin, Y.C. Chang, The influence of treatment duration on multi-walled carbon nanotubes functionalized by $\mathrm{H}_{2} \mathrm{SO}_{4} / \mathrm{HNO}_{3}$ oxidation. Appl. Surf. Sci. 257, 2401-2410 (2011). https://doi.org/10.1016/j.apsus c. 2010.09.110

27. J. March, Advanced Organic Chemistry: Reactions, Mechanisms and Structure, 3rd edn. (Wiley, New York, 1985)

28. G. Lim, K.B. Lee, H.C. Ham, Effect of N-containing functional groups on $\mathrm{CO}_{2}$ adsorption of carbonaceous materials: a density functional theory approach. J. Phys. Chem. C 120, 8087-8095 (2016). https://doi. org/10.1021/acs.jpcc.5b12090

29. Y.H. Lim, A.A. Adelodun, D.W. Kim, Y.M. Jo, Surface impregnation of glycine to activated carbon adsorbents for dry capture of carbon dioxide. Asian J. Atmos. Environ. 10, 99113 (2016). https://doi.org/10.5572/ ajae.2016.10.2.099

30. A.G. Shard, Detection limits in XPS for more than 6000 binary systems using Al and Mg Ka X-rays. Surf. Interface Anal. 46, 175-185 (2014). https ://doi.org/10.1002/sia.5406

31. Energy dispersive X-ray microanalysis (EDX/EDS). https://www.ander sonmaterials.com/edx-eds.html. Accessed 14 Dec 2019.

32. S.Y. Lee, S.J. Park, Determination of the optimal pore size for improved $\mathrm{CO}_{2}$ adsorption in activated carbon fibers. J. Colloid Interface Sci. 389, 230-235 (2013). https://doi.org/10.1016/j.jcis.2012.09.018 
33. D.W. Kim, D.W. Jung, Y.M. Jo, Preparation of activated carbon fiber adsorbent for low level $\mathrm{CO}_{2}$. J. Korean Soc. Atmos. Environ. 33, 1-10 (2017). https://doi.org/10.5572/KOSAE.2017.33.1.001

34. D.W. Kim, D.W. Jung, A.A. Adelodun, Y.M. Jo, Evaluation of $\mathrm{CO}_{2}$ adsorption capacity of electrospun carbon fibers with thermal and chemical activation. J. Appl. Polym. Sci. 134, 45534 (2017). https://doi.org/10.1002/ app.45534

35. F.S. Su, C. Lu, W. Cnen, H. Bai, J.F. Hwang ,Capture of $\mathrm{CO}_{2}$ from flue gas via multiwalled carbon nanotube. Sci. Total Environ. 407 3017-3023 ( 2009 ). https://doi.org/10.1016/j.scitotenv.2009.01.007

36. S.H. Hwang, D.W. Kim, D.W. Jung, Y.M. Jo, Impregnation of nitrogen functionalities on activated carbon fiber adsorbents for low-level $\mathrm{CO}_{2}$ capture. J. Korean Soc. Atmos. Environ. 32, 176-183 (2016). https://doi. org/10.5572/KOSAE.2016.32.2.176
37. A.A. Adelodun, Y.H. Lim, Y.M. Jo, Surface oxidation of activated carbon pellets by hydrogen peroxide for preparation of $\mathrm{CO}_{2}$ adsorbent. J. Ind. Eng. Chem. 20, 2130-2137 (2014). https://doi.org/10.1016/j.jiec.2013.09.042

38. W.C. Wilfong, C.S. Srikanth, S.S.C. Chuang, In situ ATR and DRIFTS studies of the nature of adsorbed $\mathrm{CO}_{2}$ on tetraethylenepentamine films. ACS Appl. Mater. Interfaces 6, 13617-13626 (2014). https://doi.org/10.1021/ am5031006

\section{Publisher's Note}

Springer Nature remains neutral with regard to jurisdictional claims in published maps and institutional affiliations.

\section{Submit your manuscript to a SpringerOpen ${ }^{\odot}$ journal and benefit from:}

- Convenient online submission

- Rigorous peer review

- Open access: articles freely available online

- High visibility within the field

- Retaining the copyright to your article

Submit your next manuscript at $\boldsymbol{\nabla}$ springeropen.com 